\title{
Chemical disarmament still elusive
}

THE Spring session of the United Nations Conference of the Committee on Disarmament (CCD) droned to a close in Geneva this month with little concrete progress made on the thorny issues involved in negotiating a chemical disarmament treaty. Though a proposal put forward last year by the British delegation received many general endorsements--including one from the United Statesdelegates have been marking time for the past three years awaiting a long-promised but elusive joint proposal from the United States and the Soviet Union.

Part of the problem stems from the fact that there is considerable confusion about the United States position, particularly in regard to the US Army's plans to launch a massive new programme to replace its existing chemical weapons stockpiles with so-called binary chemical weapons. The time has come for President Carter to clarify the matter.

The background is this. In the early 1970s, while US delegates were telling the $\mathrm{CCD}$ that the United States supports chemical disarmament, the US Army was requesting funds from Congress to begin building binary weaponsnerve agents made from two non-lethal components which form a deadly compound when mixed together. Not surprisingly, the negotiators were not taken very seriously. In 1974, however, Congress refused to appropriate the funds. Undeterred, the Army came back with another request the following year. This time, the House Armed Services Committee deleted the funds, but it stated that unless progress is made at the CCD talks, future requests for binary weapons would be viewed more favourably.

Consequently, no funds were requested for binaries in the budget proposed by President Ford early last year, but the Army nevertheless argued within the Administration for the programme to be reinstated in President Ford's final budget, presented to Congress last January. Ford decided not to include the funds, however, and passed the matter on to his successor. The binary programme is therefore far fom being killed off, and it still looms large over the CCD talks.

While this was going on, President Nixon and Secretary Brezhnev announced at their summit meeting in July 1974 that the United States and the Soviet Union would offer a joint initiative to break the deadlock at the CCD talks. So far, however, only two rounds of bilateral discussions have been held, the last of which took place early in April, and little progress was made.

Very tricky issues concerned with measures to police a chemical disarmament treaty are involved in the negotiations. But the time has come at least for President Carter to clear the air by announcing that the United States will scrap its plans to produce binary weapons and that the new Administration is serious about chemical disarmament.

\section{The microprocessor phenomenon}

Basil Zacharov separates fact and fiction to comment on the microprocessor 'revolution'

SINCE the introduction of the first commercial microprocessor in 1971 by INTEL the growth in number of microprocessors has been little short of phenomenal. It is estimated that the present sales, already $£ 10$ million for the European market, will grow at least tenfold by 1980 . Microprocessors are used in scientific, domestic, military and commercial applications. Conferences entirely devoted to microprocessors are now commonplace. There are professional journals which are concerned only with microprocessors. And there is hardly any research grant application with a computing or electronic content where the word 'microprocessor' does not appear somewhere or other.

The microprocessor is an electronic device, fabricated on a single small semiconductor chip, enabling certain operations to be performed on input digital data, the transformed data then becoming available either on an output data highway, or in appropriate internal registers of the microprocessor. Depending upon the choice of microprocessor, the width of the data path may be anything from 1 bit upwards, and the operations may include arithmetic instructions, logical instructions and certain others, familiar to every professional computer programmer, such as conditional and interrupt-handling operations. Thus the microprocessor is just one example of a very broad class of monolithic digital elements, using one of several large-scale integration (LSI) technologies to implement as many as $10^{5}$ components on a single semiconductor chip perhaps only $25 \mathrm{~mm}^{2}$ in area.

Not surprisingly perhaps, the very rapid evolution and exploitation of microprocessors has been accompanied by a corresponding growth in publicity, some of which has been not altogether accurate. There has emerged a mythology about microprocessors or, at the least, a certain amount of confusion. Probably the most widespread myth is that a microprocessor is a microcomputer which, still, it patently is not. Probably one should not be too pedantic about this, and anyway there are many different kinds of storedprogramme digital computer, but all of them have to have a memory, a control unit for instruction sequencing and some means of input and output as well as the processing section. So the microprocessor is nothing more than one component of a computer although, admittedly, a very powerful component indeed.

A much more dangerous myth is that it is easy to replace minicomputers by microprocessor systems and presumably, because the cost of microprocessors is so low, that it is possible to build a microprocessor-based minicomputer at a cost much lower than that of commercially-available minicomputers. And so we have seen numerous examples of minicomputers fabricated by the do-it-yourself process. The truth, unfortunately, is that, if all the component costs are really taken into account (including power supplies, circuit cards, casing and so on) and fabrication costs properly included, then it is almost impossible to compete even with the hardware costs of small minicomputers supplied to equipment manufacturers (the so-called 'naked' minicomputers, with no peripherals or other trappings). And this is not the least surprising, for minicomputer manufacturers have been making use of modern LSI components just as much as anyone else. However, if the fact is included that even the most modest minicomputer arrives with some software, then any thought that an individual can compete economically in synthesising a minicomputer just cannot be supported.

A more subtle myth is the claim that, because microprocessors are inexpensive, it is possible to produce at much lower cost a computing system that is comparable in performance to that of large general-purpose computers. Such claims are generally supported by demonstrating that microprocessor-based computing systems can be built with certain instruction execution times comparable to those of some chosen large computer. The more outspoken of those making these claims then go on to conclude that anyone 
using the large computer on a shared basis would do well to abandon this enslavement and turn instead to a 'personal' computer based on microprocessors. The millennium has, unfortunately, not yet arrived, and the reason is of course clear. It is simply that, although it is indeed possible to achieve comparable execution times for certain operations, as for example adding two integers, this is just hopelessly inadequate to achieve the performance of a large computer for calculations of a general nature.

Large computers achieve their performance precisely because of their very extensive repertoire of operations, and also because of their complex internal organisation which allows many different concurrent activities. If this performance is required, then the complexity, and hence cost, of the large system is inescapable. That is not to say that the architecture of modern large computers is the best that can be imagined, nor that a large computer is best for all purposes; just that modern large computers are fairly well matched to the requirements of most large data-processing and scientific calculations, for which a microprocessor-based alternative would be inadequate.

Of course there may be certain special computational tasks that only involve just those operations that can be implemented well with microprocessors; in this case it may well be the best choice to use the microprocessor system. But, even here, the problem has to be one which occurs frequently-otherwise it may still be much more economical to use a conventional computer inefficiently. It must be emphasised here that, just as in the case of minicomputers, large systems use LSI techniques where they can and if they are costly, it is because of all the general facilities that they possess. Microprocessors have no monopoly of LSI technology.

So what is it that microprocessors offer that has led to such an upsurge in their numbers? The most important attributes appear to be small size and low cost, but these relate to the microprocessor as a digital systems component, and not to such things as complete computers. And the advantages in using microprocessors stem from the fact that these attributes enable them to be used either where an application requires large numbers of processors or where processors need to be built into some device or other. Moreover, in applications where the processing task is completely defined and does not need to be changed, there can be a very significant economic advantage in using a microprocessor system tailored to the task rather than use a more versatile minicomputer. The advantages of microprocessors when used in these 'turnkey' systems increase tremendously when the number of similar systems is great. Such problems had been tackled in the past by building special-purpose electronic systems, but these were generally expensive and very difficult to modify. Microprocessors are not only much less costly for these purposes, but also more reliable and, more important, they allow easy evolution from one system to another by changing software.

The real benefit of microprocessors has appeared in computer peripheral devices, especially terminals, and in instrumentation of all kinds. So we have seen a dramatic change already in data presentation from instruments to human beings, and in every application where electronic systems have to respond in an adaptive way to external conditions. This introduction of so-called 'intelligence' into electronic systems has transformed the operation of a wide range of systems, from oscilloscopes to washing machines, from missiles to traffic lights, from computer terminals to automobile electronics. What was costly and complicated to do before using conventional hard-wired electronic components has now become inexpensive and relatively simple to implement.

This trend towards replacement of hard-wired electronic logic by software-programmed microprocessor-based

\section{Sorry, for copyright reasons some images on this page may not be available online}

systems is nowhere more apparent than in digital communications, itself one of the most rapidly growing technological fields. Already the use of microprocessors in coupling remote devices to computer networks is commonplace, but we are witnessing only the beginning of this trend. However, all these applications generally involve the use of only a few LSI devices for each unit of equipment, and we need also to remember the other area mentioned, where many microprocessors are used together.

For many years now there has been the idea that what is difficult to do on a conventional sequential-processing computer might be much easier to do on an array of many coupled processors all operating in parallel. Computational problems which either have intrinsic parallelism or can be suitably formulated in terms of some parallel algorithms exist in many different fields, but their solutions have been impeded by the lack of appropriate hardware. Although attempts have been made to implement parallel computer systems using conventional hardware, these attempts have been immensely costly. Now, with the advent of microprocessors, the construction of parallel processing systems has become a real economic prospect and, together with it, the promise of effective solutions to a whole new class of problems.

So, although there is a mythological element in what is being claimed for microprocessors which sometimes distracts certain sectors from the realities of the situation, it is no myth that microprocessors have made a most fundamental impact on many different fields. Microprocessors are already transforming both the construction and the exploitation of an immense range of instruments, appliances and systems, and the signs are that this trend is only a beginning. But perhaps it is as well to end on a note of caution and to mention a final myth-namely that microprocessors are easy to use, and that it is just as easy for hardware designers to employ them as it was for them to design circuits using conventional integrated circuits. What is overlooked here is of course software, which many circuit designers are seeing for the first time.

It is probably the case that, except for a few talented individuals or for very trivial tasks, it was never particularly easy to program a computer effectively in machine code, and not only are microprocessors no exception here but they are also rather primitive. The solution to this problem is well-enough understood, for example by using what are termed high-level techniques to insulate the microprocessor system user or designer from all the details of particular system components. This solution will take a long time to establish since it depends upon agreement about standards and conventions, among other factors, and these do not yet exist. However, even with high-level techniques, it will still be necessary for hardware designers to be familiar with software. Indeed, they will no longer be circuit designers but rather systems engineers. For this to come about, and for the full potential of microprocessors to be realised, we will have to adapt our educational system to meet the new needs of such systems engineers. 